\title{
Uma abordagem sobre PCHs no ensino médio como ferramenta introdutória para o ensino sobre energias renováveis
}

\author{
An approach on SHPs in high school as an introductory tool for teaching \\ about renewable energies \\ L. S. S. Oliveira; F. C. L. Ferreira; L .M. Gomes* \\ Faculdade de Física/Instituto de Ciências Exatas, Universidade Federal do Sul e Sudeste do Pará, 68507-590, Marabá \\ - Pará, Brasil \\ *luizmg@unifesspa.edu.br
}

(Recebido em 25 de fevereiro de 2019; aceito em 16 de maio de 2019)

\begin{abstract}
Este trabalho foca no ensino sobre pequenas centrais hidrelétricas como um tema gerador inicial para a abordagem dos conceitos físicos de hidrostática, hidrodinâmica e eletromagnetismo para alunos no ensino médio da rede pública estadual de ensino. Ele foi realizado com turmas do terceiro ano, em duas escolas na cidade de Marabá, no estado do Pará. Foram utilizadas simulações computacionais do Projeto Phet para complementar o entendimento dos conceitos teóricas. Os resultados obtidos evidenciaram que houve melhorias significativas quando comparados aos resultados de um grupo piloto. Houve também a preocupação em fomentar o debate sobre a mudança climática no contexto do problema da utilização das fontes não renováveis de energia e viabilidade de substituição de tais fontes por aquelas que são renováveis. Palavras-chave: Pequenas Centrais Hidrelétricas, Energia Renovável, Ensino de Física.
\end{abstract}

This paper focuses on the teaching about small hydropower plants as an initial generator subject for the approach of the physical concepts of hydrostatics, hydrodynamics and electromagnetism to students in the high school of the public school. It was carried out with 3rd year classes in two schools located in Marabá of Pará State. Computational simulations were used with the Phet Project to complement the understanding of the theoretical concepts. The results achieved showed that there have been significant improvements when compared to the results of a pilot group. There was also the concern to encourage debate on climate change in the context of the problem of the use of non-renewable energy sources and the feasibility of replacing those sources by renewable energy sources.

Keywords: small hydropower plants, renewable energy sources, Teaching physics.

\section{INTRODUÇÃO}

Atualmente, as transformações tecnológicas na sociedade estão ocorrendo muito rapidamente. Dessa forma, é cada vez mais evidente a necessidade do uso crescente da energia, sendo que a humanidade deve buscar utilizar os recursos energéticos alternativos e renováveis, como a água, o vento, as ondas do mar e a energia solar. É fundamental que as novas gerações compreendam a importância do uso de tais fontes.

Nesse sentido, a escola deve estender o seu olhar para dar aos alunos, formação significativa sobre esse tema de grande relevância na sociedade moderna, de modo que estejam comprometidos com a preservação do planeta e com a garantia de melhores condições de vida para as gerações futuras.

São consideradas fontes de energias renováveis as pequenas centrais hidrelétricas (PCHs), a energia eólica, a solar, geotérmica, a biomassa, o hidrogênio, as marés, dentre outras. Por outro lado, segundo Galdino et al. (2015) [1], “[...] a energia nuclear e os combustíveis fósseis são considerados não renováveis, pois os processos de sua utilização são irreversíveis e geram resíduos prejudiciais ao meio ambiente."

De acordo com a resolução $n^{\circ} 673$ - 04-08-2015 da Aneel (2015) [2], uma PCH é toda usina hidrelétrica, cuja potência seja superior a $3.000 \mathrm{~kW}$ e igual ou inferior a $30.000 \mathrm{~kW}$ e com área de até $13 \mathrm{~km}^{2}$, sem contar a parte externa de proteção do reservatório. Ela é uma ótima opção para a geração de energia elétrica, pois este tipo de usina reduz significativamente os impactos com o 
meio ambiente. É também adequado para rios de pequeno e médio porte que possuam uma diferença de potencial gravitacional significativa para que haja pressão e vazão suficientes a movimentação das turbinas hidráulicas.

Neste trabalho são discutidos os conceitos gerais sobre as PCHs, introduzidos em aulas ministradas à alunos do ensino médio. Nas referidas aulas foram utilizados como recursos didáticometodológicos experimentos reais e virtuais (simulações) visando subsidiar as aulas teóricas e ampliar o campo de visão dos aprendizes, possibilitando a eles, não somente um aprendizado dinâmico e inovador sobre conceitos de energia e temas correlatos, mas uma visão crítica sobre o atual contexto mundial da mudança climática e o uso desenfreado das formas de energia não renováveis, de modo a preparar essas novas gerações para uma convivência em sinergia com o planeta.

\section{FUNDAMENTAÇÃO TÉORICA}

Em linhas gerais, o funcionamento de uma usina hidrelétrica utiliza a pressão hidráulica decorrente da diferença de potencial - entre o nível do rio represado (elevação) e o nível onde estão as turbinas geradoras, para mover as hélices da turbina, e estas por sua vez, transformam energia cinética em energia mecânica (Figura 1). Nesse processo, o gerador de energia elétrica acoplado ao eixo principal da turbina e através do fenômeno físico da indução eletromagnética, possibilita o surgimento de cargas elétricas decorrentes da movimentação dos elétrons, ou seja, como é conhecida popularmente, a energia elétrica.

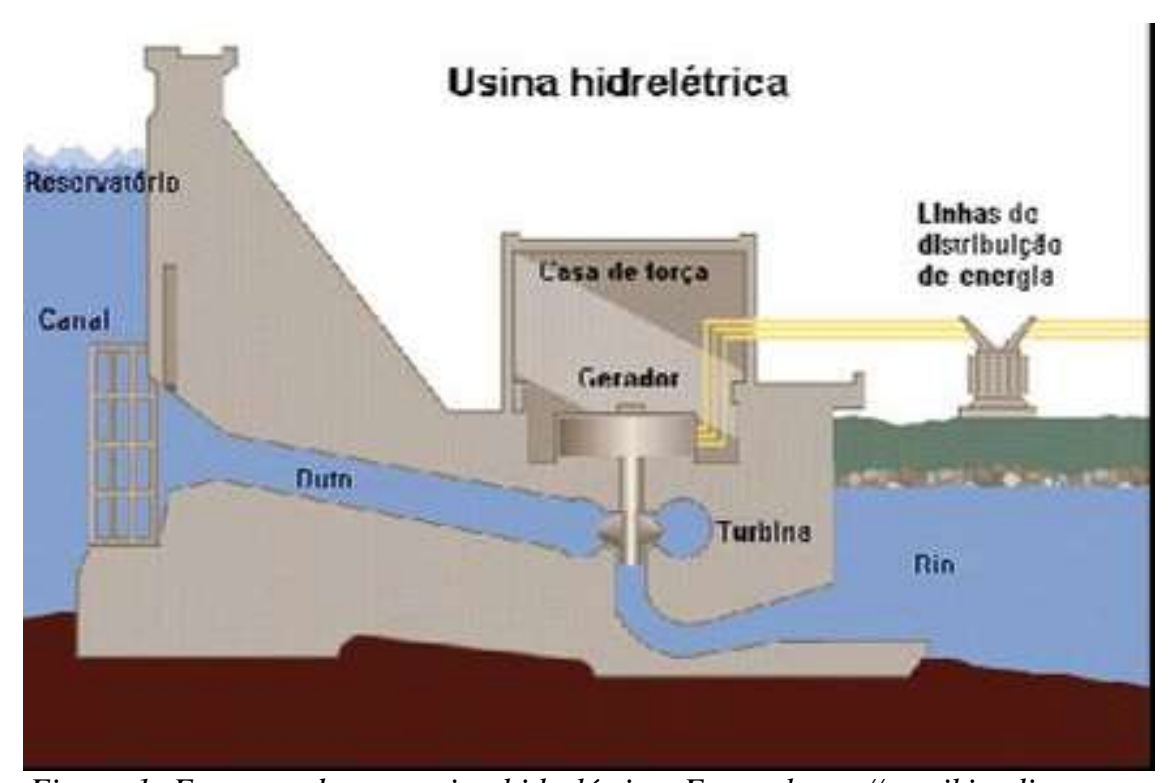

Figura 1: Esquema de uma usina hidrelétrica. Fonte: https://pt.wikipedia.org

A energia elétrica gerada decorrente da movimentação de cargas elétricas alimentará a subestação central da hidrelétrica com intuito de elevar a tensão do sistema. No decorrer do deslocamento dessas cargas até as subestações locais, fatores tais como resistência elétrica, efeitos termostáticos, dentre outros, poderão produzir perdas acentuadas de tensão [3]. Ao chegar as subestações locais, os transformadores equilibrarão as tensões a níveis adequados aos aparelhos elétricos, ou seja, adequados as fases de tensões.

A turbina é uma peça fundamental para a geração de energia elétrica, pois é responsável por transformar a energia mecânica do fluído em trabalho de eixo. Em uma hidroelétrica é colocado ao eixo de rotação um gerador elétrico. Um dos tipos mais importantes de máquinas elétricas rotativas é o gerador síncrono, máquina capaz de converter energia mecânica em elétrica quando operada como gerador e energia elétrica em mecânica, como motor. Geradores síncronos são utilizados em todas as usinas hidrelétricas e termoelétricas. O nome "síncrono" se deve ao fato de esta máquina 
operar com uma velocidade de rotação constante e sincronizada com a frequência da tensão elétrica alternada nos terminais da mesma. [4]

Michael Faraday afirma que "A corrente elétrica induzida em um circuito fechado por um campo magnético, é proporcional ao número de linhas do fluxo que atravessa a área A envolvida do circuito, na unidade de tempo" [5], ou seja, ele percebeu que sempre que uma força eletromotriz induzida (fem) aparecia em um circuito, estava ocorrendo uma variação do fluxo magnético através desse circuito. Mais precisamente Faraday verificou que, se durante um intervalo de tempo $\Delta$ t o fluxo magnético através de um circuito variar de $\Delta \varphi$, haverá, nesse circuito uma fem induzida dada por:

$$
\varepsilon=\Delta \varphi / \Delta t
$$

Sendo que o fluxo magnético é dado por meio da relação,

$$
\varphi=\mathrm{B} \cdot \mathrm{A} \cdot \cos \theta
$$

Henrich Lenz em Griffiths (2011) [5] afirma que "o sentido da corrente é o oposto da variação do fluxo do campo magnético que a gera". Ele percebeu que ao afastar um campo magnético de uma espira a mesma irá produzir um campo que se opõe a diminuição e vice-versa. Com base neste princípio um gerador consome tanto mais energia mecânica quanto mais energia elétrica ele produz (sem considerar a energia perdida por atrito e pelo efeito Joule). Já que temos um campo na espira que se opõe a variação do campo magnético, então temos um trabalho realizado e isso nos leva a compreender que quanto mais o gerador gera energia, mais será o trabalho necessário para manter o eixo do gerador rotacional.

O gerador de uma hidroelétrica, aqui no Brasil, tem uma rotação de 60 ciclos por segundo ou $60 \mathrm{~Hz}$. Estes ciclos são alternação entre valores positivos e negativos no sistema e é por isso que o tipo de energia que recebemos em nossas residências é alternada.

\section{MATERIAL E MÉTODOS}

Este trabalho caracterizou-se por uma análise qualitativa e quantitativa onde foram utilizados questionários (Apêndice A) sobre energias renováveis e, especificamente, sobre os conhecimentos prévios que os alunos detêm (ou não) a respeito das Pequenas Centrais Hidrelétricas. O público alvo foi de 407 alunos do $3^{\circ}$ ano do Ensino Médio. Para a coleta de dados, aplicou-se o Termo de Assentimento Livre e Esclarecimento (TCLE) com os envolvidos na pesquisa. A escolha de alunos do $3^{\circ}$ ano se justifica devido à maioria dos conceitos sobre Eletricidade e Energias estarem presentes na grade curricular da disciplina de Física deles. As instituições educacionais escolhidas para a execução dessa pesquisa foram as duas escolas da rede pública estadual de ensino médio da cidade de Marabá Dr. Gaspar Viana e Plínio Pinheiro.

De acordo com Ausubel (2000) [7], baseado numa linha cognitivista, a aprendizagem ocorre por meio da agregação dos conteúdos de forma substantiva e não literal, na estrutura cognitiva do indivíduo, através da conexão com uma estrutura de conhecimentos específica, chamada de subsunçor, o qual pode ser um conceito, ideia ou proposição existente na estrutura cognitiva do indivíduo, que auxilia na ancoragem da nova informação. Assim, com a utilização de experimentos, pode-se estabelecer uma zona de desenvolvimento proximal fazendo com que o aluno tenha um maior conhecimento real possibilitando ao professor elevar o desenvolvimento potencial do aluno [8].

Em síntese, o trabalho foi realizado através das seguintes etapas:

$\checkmark$ Realização de um questionário inicial (triagem) com alunos e professores da disciplina Física (5 no total), onde foi verificada a opinião deles sobre as energias renováveis;

$\checkmark$ Aulas foram ministradas abordando o assunto energias renováveis com o foco nas PCHs. Como ferramenta auxiliar ao aprendizado dos alunos foram utilizadas as simulações virtuais Hidrostática e Hidrodinâmica, eletricidade e magnetismo e PCHs com o uso do Software livre da Universidade do Colorado Interactive Simulations Phet [6]. Nesta etapa, as turmas foram divididas em dois grupos (A e B). No caso do grupo B (piloto), as aulas foram realizadas sem a simulação virtual; 
$\checkmark$ Realização de provas sobre as aulas para aferir o rendimento dos alunos dos grupos A e B;

$\checkmark$ Aplicação de um segundo questionário, de caráter qualitativo, para verificar do nível de compreensão crítica dos alunos sobre as PCHs e importância do uso das energias renováveis. Também verificar se ocorreram mudanças nas concepções dos alunos (verificadas no $1^{\circ}$. questionário).

$\checkmark$ Análise dos resultados da pesquisa

Como já abordado, as simulações virtuais trataram de conceitos de Hidrostática e Hidrodinâmica como Pressão em fluídos, Pressão Atmosférica, Tipos de Escoamento, Vazão de um escoamento, Equação da continuidade e Equação de Bernoulli, dentre outros (Figura 2).

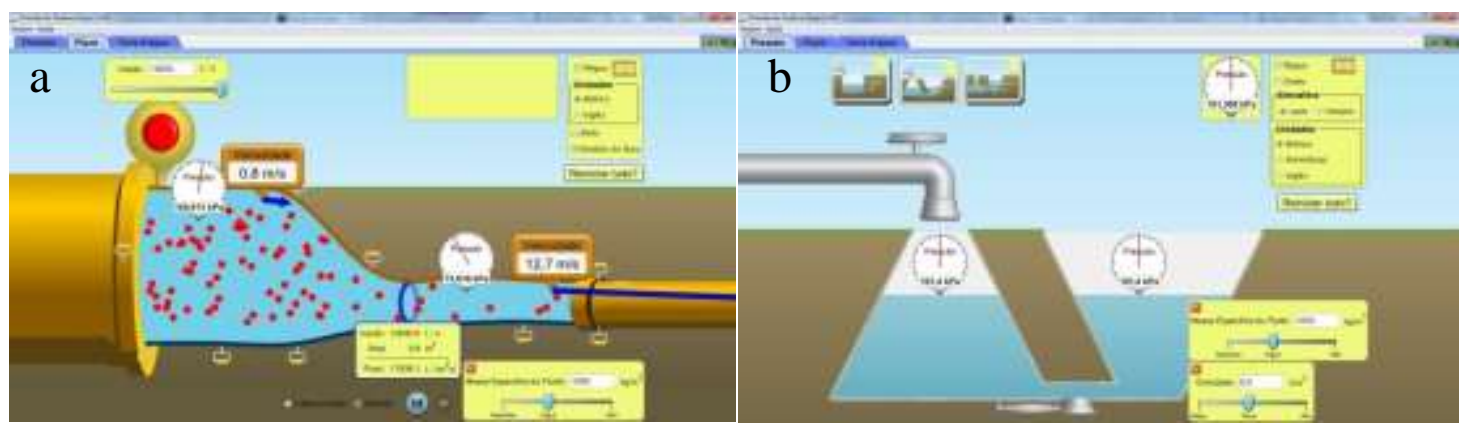

Figura 2: Simulações no Phet. (a) Fluxo (b) Pressão.

Em um segundo momento, foram discutidos conceitos através da simulação sobre eletricidade e magnetismo (Figura 3) tais como resistência elétrica, magnetismo e indução eletromagnética.

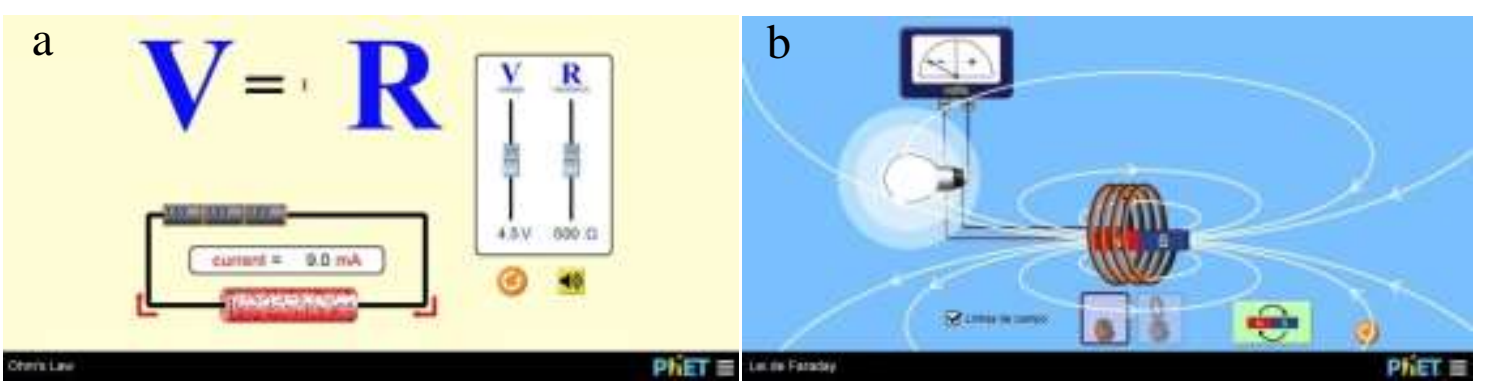

Figura 3: Simulações no Phet. (a) Lei de Ohm (b) Lei de Lenz-Faraday.

Finalmente, foram abordados assuntos como o gerador elétrico e eletroímãs (Figura 4), com relação direta com a geração de energia nas PCHs.

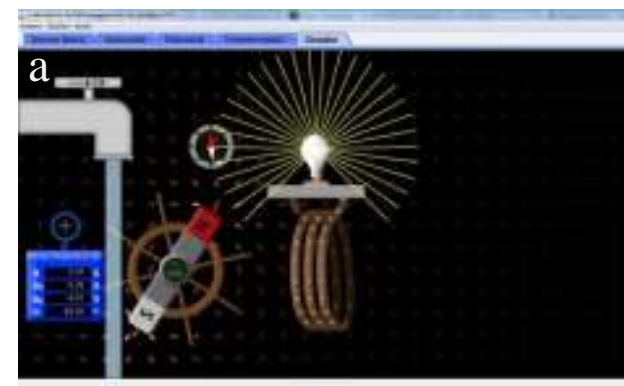

*

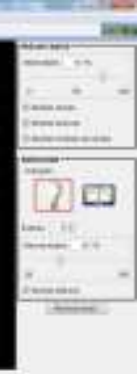

no Phet.

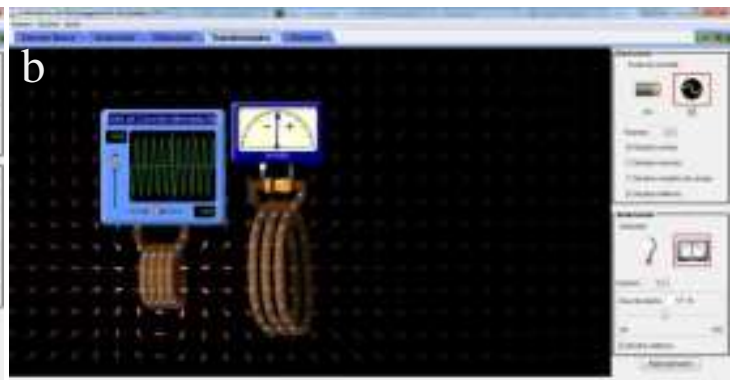

(1) *

Figura 4: Simulações no Phet. (a) Gerador (b) Eletroimãs.

\section{RESULTADOS E DISCUSSÃO}

Com relação ao questionário inicial (triagem), ao serem interpelados sobre o que são energias renováveis, 43,24\% dos alunos responderam que não sabem de fato o que significa esse assunto. 
Isso foi motivo de grande preocupação nesta pesquisa, uma vez que este é um assunto bastante recorrente em telejornais, periódicos e outros meios de comunicação.

Quando perguntados sobre o uso adequado das energias renováveis (questão 6), 20,15\% dos alunos entendem que são nocivas e 29,24\% (Figura 5) acham que são rentáveis (o que evidentemente não é o caso, uma vez que o custo em kwh das energias renováveis ainda é muito elevado), o que corrobora o resultado da primeira pergunta.

6. Qual a sua opinião com relação à utilização de energias renováveis?

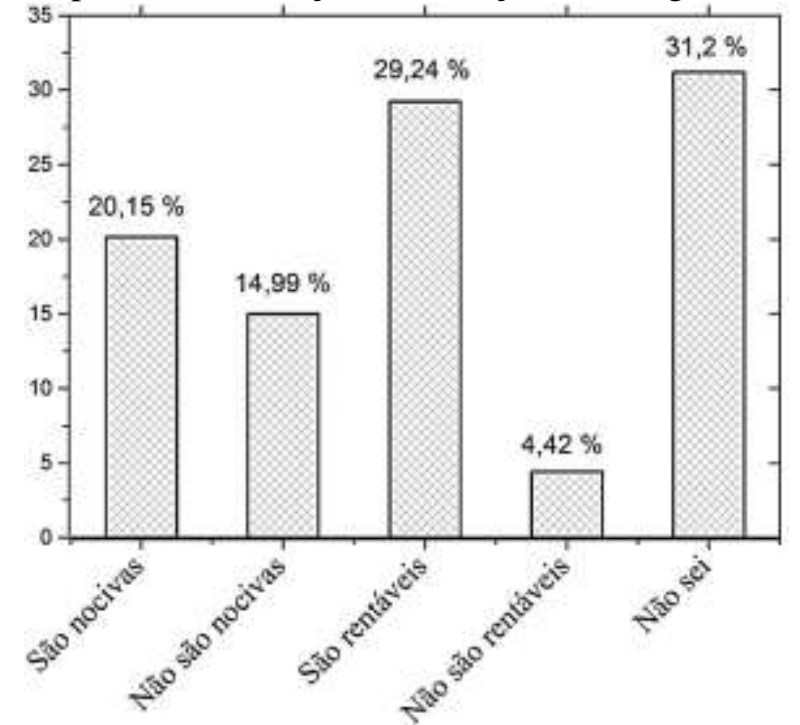

Figura 5: Percentual de respostas da questão 06 do questionário 01 (triagem).

Quando os docentes foram questionados sobre o conhecimento de energias renováveis, o resultado foi preocupante, pois $75 \%$ afirmaram desconhecer o assunto, fato que certamente é inadmissível nos dias atuais. A partir deste resultado, fica claro o desconhecimento da parte dos alunos deste importante assunto, uma vez que a maior parte dos seus professores de Física não domina totalmente $\mathrm{o}$ assunto e, consequentemente, não abordam o tema nas aulas.

Posteriormente a ministração das aulas e das simulações, as turmas foram submetidas a uma atividade avaliativa para aferir o nível de entendimento dos conceitos. É importante destacar que ambos os grupos tiveram a mesma carga horária de aulas (expositivas para o grupo B e expositivas mais simulações para o grupo A). A avaliação consistiu de 7 questões de Física de múltipla escolha relacionadas ao tema proposto abordado em sala de aula. Notadamente, o grupo A destacou-se em relação aos resultados do grupo B, ou seja, os alunos que tiveram as aulas teóricas e realizaram as simulações demonstraram maior desempenho na avaliação. A Figura 6 mostra o percentual de acertos por questão de ambos os grupos. 


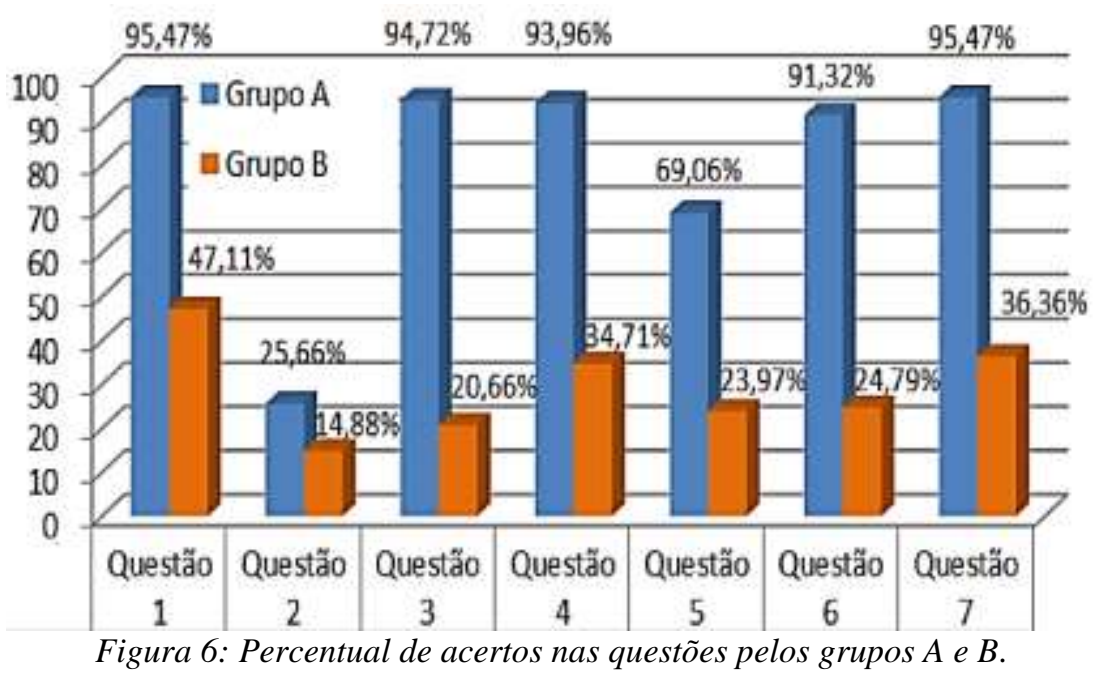

O grupo A obteve uma média geral de $80,8 \%$. O desvio padrão de 24,16 . Por outro lado, a média do grupo B foi $28,9 \%$, com desvio padrão de 10,18. Apesar do desvio padrão do grupo A ter sido elevado com relação ao grupo B, é notório que a média deste grupo foi bastante elevada. Uma provável solução para a redução dessa dispersão nos resultados seria trabalhar de forma mais intensiva conceitos básicos relacionados ao tema (onde os alunos apresentaram as deficiências), de modo a obter uma melhor homogeneização dos resultados.

Finalmente, foi proposto aos alunos do grupo A (não foi aplicado ao grupo B já que eles não tiveram as simulações virtuais nas aulas) um questionário final com objetivo de se avaliar a importância das simulações no seu aprendizado sobre o tema.

Quando perguntados se as simulações contribuíram (ou não) para o aprendizado a respeito das energias renováveis e PCHs quase $90 \%(89,06)$ dos alunos responderam que sim, evidenciado que a correta simulação de fenômenos físicos em sala de aula é pratica, e de fato facilita o aprendizado, complementando este. Cabe destacar que a simulação envolve conceitos de física (Hidrostática e Hidrodinâmica, eletricidade e magnetismo) trabalhados nas aulas, os quais foram "reforçados" aos alunos. Já aqueles que responderam "não facilita", afirmaram que estão acostumados as aulas tradicionais e que apesar das simulações serem interessantes, acabam confundindo a assimilação dos conceitos.

Observou-se também a repercussão positiva entre os alunos sobre as aulas com proposta de ensino inovador, no caso a ênfase nas PCHs e sua importância para a sociedade atual.

Durante as aulas, pode se verificar a empolgação dos alunos em poder tratar em sala de aula de tema tão atual e importante dentro do contexto da mudança climática. Ao serem perguntados se o ensino de energias renováveis contribuiu para o ensino aprendizagem de física, quase totalidade respondeu afirmativamente $(98,11 \%)$. Cabe destacar aqui que é totalmente viável, através de simulações, tornar as aulas mais divertidas, aprofundar a discussão do tema em questão, e conscientizar a turma sobre a riqueza deste e importância no contexto atual. Lembrando sempre que as simulações devem complementar a aula, não ofuscando sua parte expositiva.

O estudo de PCHs se justifica pelo fato de que, como uma fonte de energia renovável, está relacionado a um tema atualíssimo, que é a mudança climática. Explorar o mundo da física também é um meio de propor aos discentes um caminho para que, futuramente, possam fazer ciência no meio acadêmico ou profissional. Além disso, permite que os estudantes vejam ciências no dia-adia, quebrando a visão de que a ciência é restrita a uma elite de seres isolados e iluminados e distantes dos demais.

\section{CONCLUSÃO}

No trabalho, ficou evidente que o entendimento dos alunos e professores a respeito das energias renováveis não era satisfatório, ou seja, não tinham um domínio efetivo desse conteúdo. Assim, foi possível mostrar aos alunos e seus professores que é possível através da utilização de ferramentas 
simples (no caso as simulações virtuais) ampliar o debate sobre um tema, de modo dinâmico e interativo, possibilitando aos alunos uma aprendizagem divertida e eficiente.

Pode-se verificar uma melhor interação dos alunos com os conteúdos trabalhados. Observou-se que a utilização das simulações ajudou na compreensão e assimilação do conteúdo ministrado, uma vez que ela complementa o aprendizado da teoria.

Um aspecto interessante, observado durante as aulas, é que os discentes, durante as simulações, demostraram grande interesse em manusear os simuladores e interpretar os resultados, passando de uma atitude passiva para proativa,

Finalmente, o fato de se ministrar aulas sobre PCHs, possibilitou uma clara compreensão da importância do seu uso em nossa sociedade, do porquê da opção das fontes de energia renováveis em detrimento das fontes não renováveis e, também, uma visão crítica sobre a mudança climática e seus possíveis desdobramentos no nosso planeta.

\section{REFERÊNCIAS BIBLIOGRÁFICAS}

1. Galdino MAE, Lima JHG, Ribeiro CM, Serra ET. O Contexto das Energias Renováveis no Brasil. Revista Direng, p. 17-25, 2015. Disponível em: <http://www.cresesb.cepel.br/publicacoes/download/ Direng.pdf>. Acesso em: 14 set. 2018.

2. Brasil. Aneel. Resolução normativa No 673, de 4 de agosto de 2015. Brasilia, BSB, 2015. Disponível em: <http://www.aneel.gov.br/cedoc/ren2015673.pdf>. Acesso em: 15 dez. 2018.

3. Pacheco F. Energias renováveis: breves conceitos. C\&P, p. 4-11, 2006. Disponível em: $\langle\mathrm{http}: / /$ ieham.org/html/docs/Conceitos_Energias_renováveis.pdf>. Acesso em: 11 set. 2015.

4. Martins AP. Usina hidrelétrica de Tucuruí: uma abordagem sobre os princípios físicos envolvidos na produção e transmissão da energia elétrica. Monografia (TCC)-Universidade federal do Pará, Belém, 2012.

5. Griffiths DJ. Eletrodinâmica. 3. ed. São Paulo: Pearson, 2011.

6. Phet: Interactive Simulations. 2015. University of Colorado Boulder. Disponível em: <https://phet.colorado.edu/pt_BR/>. Acesso em: 23 dez. 2018.

7. Ausubel DP. Aquisição e Retenção de Conhecimentos: Uma Perspectiva Cognitiva. 1. ed. New York: Paralelo Editora, 2000.

8. Ivic I. Fundação Joaquim Nabuco. Lev Semionovich Vygotsky. Recife: Fundação Joaquim Nabuco : Ed. Massangana; 2010. 


\section{APÊNDICE A}

\section{Questionário 1}

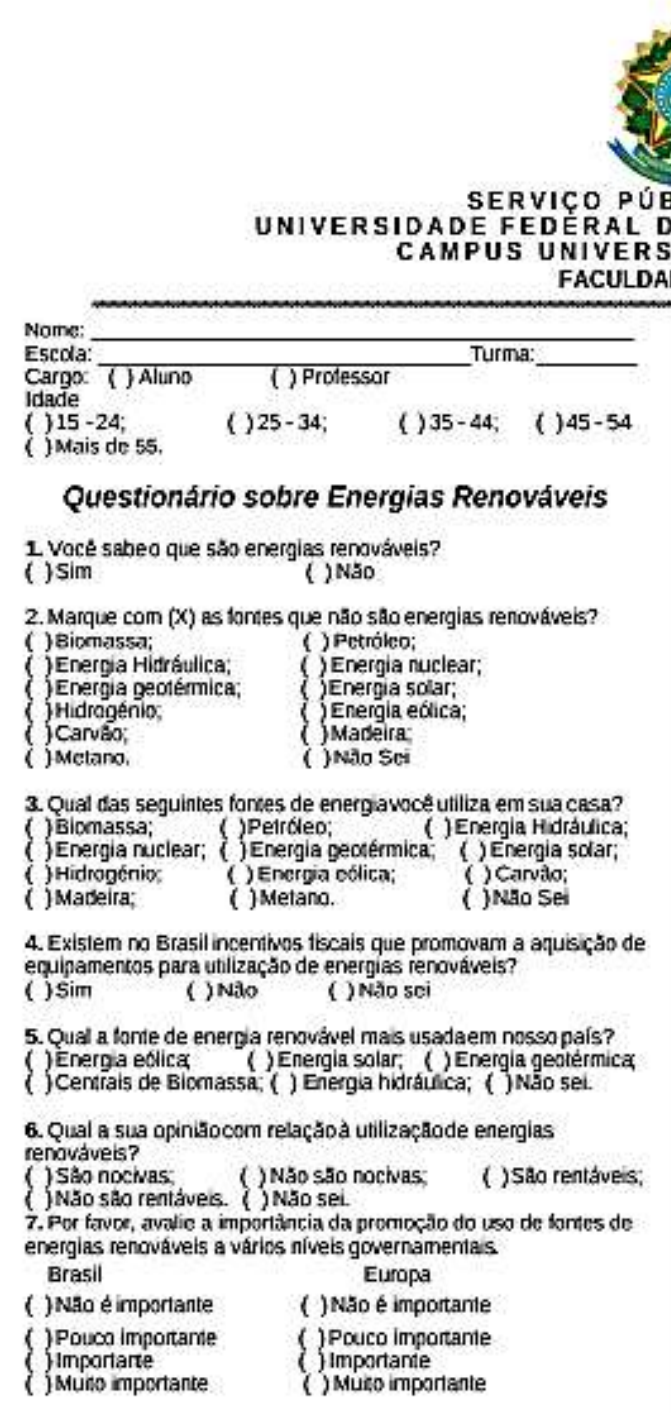

8. Na sua opiniaso, qual a porcentagem do consumo global de enerpa em que devlamos apenas ictizar tonies de energia $\begin{array}{llll}\text { (1) } 10-203 \% & \text { () } 20-40 \% ; & \text { () } 40-603 \% & \text { () } 60-803 \%\end{array}$ () $80 \%$ ou mais. ( ) Nàd sei

9. Considera que o impacto do uso de tontes de energia renowável na alteraçăo gicbai do clima e: $\begin{array}{lll}\text { () Negarmo, } & \text { () Sem efeito; } & \text { () Positwo; }\end{array}$

10. Acha que as soluçbes com energias renowáveis podem conduzir a uma disinbuiç̧ăo mas justa das riquezas mundias?

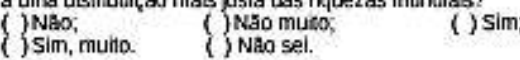

\section{E DO PARÁ}

FEDERAL DE MARABA

11. Pensa que as soluçêes corn energias renovatucis podem ajudar o desenuolvimento a văros níveis govemamentas?

Brasil

() Nằ mejito () Nầ muto

() Sim

\{ Sim multo

12. Considera que as soluoties com energias renovíveis podem ajudar a libertarnos de dependermos do uso do petróleo e de oisros combustiveis tosses?

Brasil

() Nấo

() Năo muìto

\{ Sim

\{ Sim muito

() Náo sei.

Europa

() Nato

() Năo mulio

$\left\{\begin{array}{l}\text { Sim mulo } \\ \text { Sim muto }\end{array}\right.$

13. Considera que o irwestimento pessoal em energias renowávels seja um bom investimemso para o tuburo?
() Mầ
() Nàेo muito
() $\sin$
() Sim muito
() Nan sel

14. Estáde acordoem ter uma centralperto da sua residéncia?

Eólica

() Năo

() Năo muito

( ) $\mathrm{Nim}$

() Sim muit

(3) Näo sei.

Solar

() Nắo

( ) Nắ muito

() $\sin$

() Sim muto

15. Qual a sua percepçăo do custo de uma central energétca?

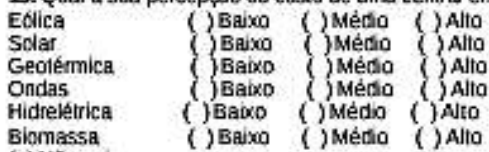

Biamassa

() Baixo () Médio () Alto

(J)án 5 -

16.Percepçăodo impactovisual de uma centralna paisagem

Eolica () Baixo () Médio () Alto

Solar

Ondas

Hidrelétrica

Biomassa

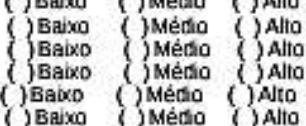

() Năo sei. 


\section{Avaliação}

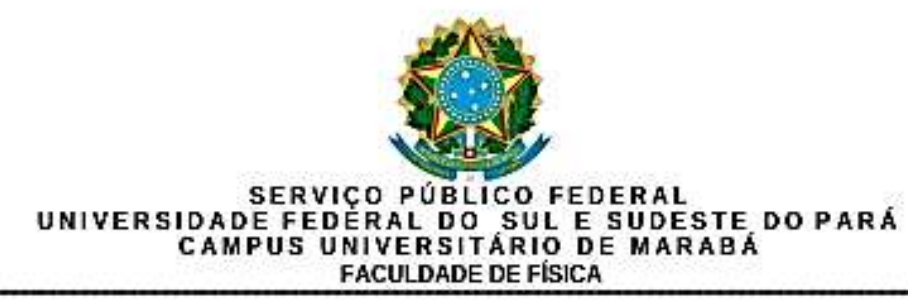

Nome:
Escola:
Cargo:

Idade

() $15-24$;

()Mais de 55 .

() Prolessor

Turma:

\section{Questionário sobre Energias Renováveis $\mathrm{PCH}$}

1 (ENEMr1998) Na figura ababo esa esquematizado um tịo de usina tutizada na geraçঞo de eletricidade.

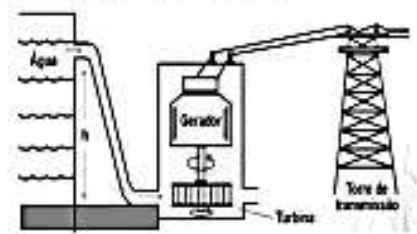

Analisando o esquema, é possível idemificar que se trata de uma usina:

aX Jnidreletrica, porque a d́gua corrente baixa a temperatura da

bX ) hidrelécrica, porque a usina taz uso da energia cinética da

cX. I termoctétricas, porque no movimento das turbinas ocorre aquecimento.

dx J édica, porque a turtina é movida pelo mosimento da água.

eX J nuclear, porque a energia é obitida do núcleo das moléculas de água.

2. (ENEM/1998) A eficiencia de uma usina do tho da representada na figura da questăo anterior, é da ordem de 0,9, ou seja, 90\% da Jo processo 5e transtorma em erergia elética. A usina JiParaná, do Estado de Rondonia, tem porencia instalada de $\mathbf{5 1 2}$ Milhōes de Wart e a barragem tem altura de aproximadamente $120 \mathrm{~m}$. A vazlo do Jrparaná, em litros por
segundo, deve ser da ordem de:

aX ) 50 ; b) ( ) 500 ; c) ( ) 5.000; dX ) 50.000; eX J 500.000

3. (ENEM/1998) No processo de obtençào de eletricidade, ocorrem varias transformaçces de energia. Considere dias delas:

1. cinetica em ejétrica II. Potencial gravitacional em cinética

ax ) a água no nivel he a furtina // a gerador e a torre de distribuccho

bX ) a agua no nivel he a turtina // a urbina e o geredor

c) J a urbina e o gerador /f a turtina e o gerado

dX J a turtina o o gerador $\|$ a água no nivet th $\mathrm{e}$ a furtina eX ja gerador e a torre de disirbuiçăo i/ a água no nível he a turbira
4. 'A gigus de março definem se fatta luz este ano" Esse foi o titulo do jornal en circulaçăo nacional, pouco antes do início do racionamento do consumo deenergia eletrica, em 2001. No Brasil, a relacto entre a produçato de eleircidade e a utlizaçalo de recursos hidncos, estabelecida nesta manchete, se just tcapor que.

aX ) a geraçăo de eletricidade nas usinas hidrelétricas exige a manustenç̧o de um dado fluxo de água nas barragens.

bX) ) osistema de traramento da água e sua distribuiçăo consomem grande quantidade de energa elérnca.

c)( ) a peraçato de eletricidade nas usinas temoelćtricas ufliza grande volume de ́́qua para refrigeraçăo.

dX $)$ o consumo de agua e de energia elétrica utilzadas na indístria compete com oda agncultura.

eX J e grande o uso de chuveiros elétricos, cujo a operaçăo implca atbundarite consumio de ingur.

50 funcionamento dos gerartores das usinas hidrelétricas baseia se no tencmeno da induçăso eleiromagnéica. Podese observar esse tenomeno ao se movimemar um ima e Lma espira em uma corrente eléirica de insensidade L, como mostra na tigura.

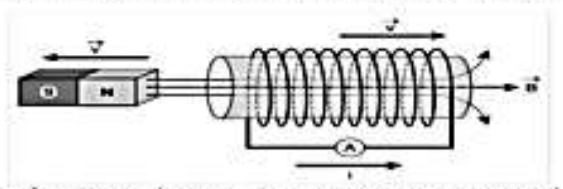

A fim de se obcer uma corrente com o mesmo sentido da apresentada na tigura, utiizando os materials, oufra posshilidadeé mover a espira para a

aX ) a esquerda e o imă para a direta com polandade irmertida; bX direlia e o ima para a esquerda compolaridade invertida: c) Jesquerda e o imá para a esquerda com mesma polaridade. dX ) direita e manter o ima en repouso com polanidabe irmertida: eX j esquerda e manter o ima em repouso com mesma polaridade;

6 (EREM2002) Em izinas hidreëtricas, a queda ớagua move turbinas que acionam geradores. Em usinas eólcas, os geradores stip acionsidos por hétices movidas pelo vento. Na cormersto direta solarelétrica săo celulas tocovoikaicas que produzem tensas tem en comum o tato de

a) J nito provocarem impacto ambiental

bX \} independerem de condiçoes dimaicas

c) J a energia gerada pode ser amaxenada

dX Jutilizarem tomtes de energas renováveis

eX jdependerem das Reservas de combustiveis tosseis.

7. Para a produçăo de energia elétrica, tazse necessário represar um rio, construindo uma barragem, que irá formar um reservatório (lago). A ápua represada moverá as turbinas, que produziram a energia. Enre do impactos ambientas calsados por esta construçion, podemse drestacir.

a) aumento da temperatura local e chuva ácita; c) Y alagamemo de grandes áreas e aumeno do nivel dos occinos;

dX) alteraçato do curso natural do no e pousçăa atmostérica;

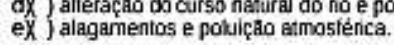




\section{Questionário 2}

\section{EAst \\ SERVICO PÚBLICO FEDERAL}

UNIVERSIDADE FEDERAL DO SUL E SUDESTE DO PARÁ

CAMPUS UNIVERSITARIO DE MARAB

FACULDADE DE FISICA

Pesquisa de Opinito

08 . 0 imulator faclita 0 aprendizado emenergias renovávelscom entiase em usinas hidrelérncas?

aX ) Năo tacilita $\quad$ b) () faclita muto

09. Já ulinha viso algum smulator sendo usato para ausollar as aulas de fisica?

a) ) $\mathrm{sim}$

b) () Năo

10. Voct artha que o eresino de energins renoviveis cortibuiu para o ensino-aprendizagem de ilsica?

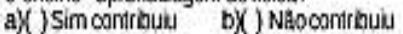

11 Gostaria que as smulaçles fossem mais ullilaadas nas aulas de

fisica?
aX) ) Sim
b) ( ) Năo

12 O uso do simulator facilitou a compreensăo do éfeitofoto eléricico?
a) Regular
b) () Bom
c) jótino

13. 0 simudadortacilitou o entendimento dos conceitos básiccos para

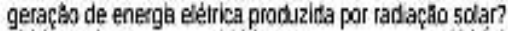
a) Regular
b) $)$ Exm
c) jótimo

14. Qual a importåncia do uso do simulador em sala de aula, para encender a tunconamerno de uma usina extilica?

a) Regular bX Bom cX) Jótimo

15. Como vocé dassificarix a compreensto de cnergin oblica corn uso do simuladx?

aX) Regular bX) Bom $\quad$ cX) J demo 